\title{
Socio-Demography Characteristics and Prevalence of Brucellosis Among Community Members in Kenya. A Case of Mandera East Sub-County, Mandera County, Kenya
}

\author{
Abdirahman S. Abdalla \\ Department of Community Health and Epidemiology, Kenyatta University, P.O. Box 43844-00100, Nairobi, Kenya \\ dr.asabdalla@gmail.com
}

\begin{abstract}
Brucellosis is an infectious debilitating, acute or sub-acute febrile illness usually marked by an intermittent or remittent fever accompanied by malaise, anorexia and prostration, and which, in the absence of specific treatment, may persist for weeks or months. The aim of this study was to determine the relationship between SocioDemography Characteristics and prevalence of brucellosis among community members in Kenya. A case of Mandera East Sub-county, Mandera County, Kenya. The study was descriptive cross sectional study which collected both qualitative and quantitative data from where a sample of 420 respondents was systematically selected from heads of 2,617 households form Mandera East Sub-county. The study instruments included questionnaire, Focus Group Discussion guide and Interview Guide. Blood samples were screened for brucellosis using Rose Bengal Plate Test (RBPT) and the positive sera were subjected through Serum Slow Agglutination Test (SSAT) which acted as a confirmatory test. Data was analyzed using SPSS Version 20 and results of the study presented in frequencies and percentages in Tables and Figures. Ethical issues were observed and consent sought from the respondents. Rose Bengal Plate Test (RBPT) indicated a prevalence of 24.8\% (95\% CI: 20.0-29.6) and Serum Slow Agglutination Test (SSAT) indicated that the prevalence was at $14.3 \%$ (95\% CI: 8.7-19.9) among the respondents. The study showed that the seroprevalence was higher among the male respondents $(98 \% ; n=103)$ as detected through RBPT and (98\%; $\mathrm{n}=57$ ) confirmed through SSAT. There was significant relationship between the gender and seroprevalence as tested through RBPT $(\mathrm{P}<0.001)$.
\end{abstract}

Keywords: Socio-demography characteristics; Community members in Kenya; Prevalence of brucellosis.

(c) (1) CC BY: Creative Commons Attribution License 4.0

\section{Introduction}

Brucellosis is an infectious debilitating, acute or sub-acute febrile illness usually marked by an intermittent or remittent fever accompanied by malaise, anorexia and prostration, and which, in the absence of specific treatment, may persist for weeks or months [1]. It is a zoonotic infection caused by the bacterial genus Brucella that are transmitted from animals to humans by ingestion through infected food products, direct contact with an infected animal. Other common routes of infection include direct inoculation through cuts and abrasions in the skin, inoculation via the conjunctival sac of the eyes, or inhalation of aerosols. Humans are accidental hosts, but brucellosis continues to be a major public health concern worldwide and is the most common zoonotic infection [2]. Brucella are small aerobic intracellular coccobacilli, localize in the reproductive organs of host animals, causing abortions and sterility. They are shed in large numbers in the animal's urine, milk, placental fluid, and other fluids [3].

The main domestic animals that are affected include cattle, sheep, goats, pigs and dogs with the principal manifestations of reproductive failure; abortion or birth of unthrifty offspring in females, orchitis and epididymitis in males [4]. Six major Brucella species are known to cause disease in humans:Brucellaabortus, B. melitensis, B. suis, $B$. canis, B. ovis and B. neotomae [5] all of which circulate in animals. Susceptibility to brucellosis in humans depends on various factors, including the immune status, routes of infection, size of the inoculum and, to some extent, the species of Brucella. In general, B.melitensis and B.suisare more virulent for humans than B.abortus and B.canis, although serious complications can occur with any species of Brucella.

The African Continent faces unique problems and obstacles to enter international world markets for animals and animal products, the most important being the continued presence of most of the trade-sensitive animal diseases in Africa and the inability of many African countries to guarantee the sanitary measures for safe trade required by trading partners. Studies done in Kampala revealed a prevalence of $12.6 \%$ in informally marketed milk as well as a total of 652 cases of human brucellosis from the Kampala based regional referral hospital over a period of three years [6].

In Kenya, the distribution of brucellosis cases by 2010 was Central 24\%, Coast 20\%, Nairobi 17\%, North Eastern 11\%, Rift Valley 23\%, Eastern 5\%, Western 0\%, Nyanza 0\%. On 17th June of 2011 (Legal notice No. 68), brucellosis was gazetted as a notifiable disease in Kenya under the animal diseases act (Cap. 364) [7]. With this act, all identified cases of brucellosis must be reported to the department of veterinary services. However, in Mandera, in the former North Eastern Kenya the available data on brucellosis is not adequate enough to inform an effective control processes. The cultures of some community that encourages consumption of raw livestock products such as 
whole blood and raw milk, the free range production system practiced in most parts of the county helps to maintain the disease in both animal and human populations. Livestock-wildlife interaction especially during free grazing cattle rustling, porous borders limiting control efforts in adequate diagnostic technique do not give a true picture of Brucellosis presence/absence [8]. Therefore, this study sought to test whether there is a relationship between SocioDemography Characteristics and Prevalence of brucellosis among Community Members in Kenya. A Case of Mandera East Sub-county, Mandera County, Kenya

\section{Literature Review}

Social demographic characteristics associated with prevalence include age, sex, education level and socialeconomic status and others. Brucellosis in the Mediterranean, chiefly due to B melitensis, has the highest age/sexrelated incidence in males in their mid-20s. A report from northern Saudi Arabia found that cases of brucellosis occurred mainly in individuals aged 13-40 years with younger than 13 years and less in those aged 40-60 years [9]. The predilection is not universal, given that $60 \%$ of cases in Jordan occur in individuals younger than 24 years. Elderly individuals with acute localized brucellosis are particularly likely to manifest destructive localized brucellosis of the spine [10]. Brucellosis is generally uncommon in infants. Brucellosis may be more common in children in developing countries because of lack of pasteurization and working in an agrarian society [11].

Brucellosis is more common in males than in females. Young adult males predominate in most series of patients with brucellosis compiled in areas of endemic disease but the reasons for increased risk are not known. Food-borne brucellosis is not limited according to age or sex and is found in women and men in equal numbers [9].

Given that symptoms and signs of brucellosis are nonspecific, cultures and serology are usually necessary for diagnosis. Diagnosis of brucellosis is definitive when Brucella organisms are recovered from blood, bone marrow, or other tissue. Some Brucella species require 5-10\% carbon dioxide for primary isolation. Because of the ease of aerosol transmission, any potential Brucella specimens should be handled under a biohazard hood. The sensitivity of blood cultures with improved techniques such as the Castaneda bottles is further improved by the lysiscentrifugation technique. With these methods, the sensitivity is approximately $60 \%$. Subcultures are still advised for at least 4 weeks.

Serologic testing is the most commonly used method of diagnosing brucellosis. It includes; MRT which is used to screen for Brucellosis in herds of dairy cattle. If applied to test milk from individual cows, the milk should be diluted in already negative milk before testing. The use of MRT is such that an intense blue colour in the cream layer and a mild blue coloration in the skim milk layer indicate a positive result. A negative result is indicated by equal intensity in colour in both layers or, the blue coloration is more intensive in the skin milk layer; Milk Plate Test (MPT) in goat milk. This test is a modification of MRT also used in goat milk. The test is highly sensitive and the equipment used in the serum agglutination plate method may be used Blake, et al. [12] Rose Bengal Plate Test (RBPT). In this test antigens used consist of Brucella cells stained with Rose Bengal suspended in a buffer at $\mathrm{pH}$ 3.65. Positive sera are subjected to the SSAT and CFT [13]; Serum Slow Agglutination Test (SSAT). This test is conducted by dilution of serum in phenolised saline in agglutination tubes and adding equal volumes of the standard antigen that is whole cell antigen. It is not effective in individual animals due to its deficiencies for instance, detecting non-specific antibodies as well as specific antibodies form Brucella infection and vaccination, during incubation it is the last test to indicate presence of infection. [14]; Enzyme Linked Immunosorbent Assay (ELISA). The assay employs both whole cell and purified lipopolysaccharide antigens and a variety of immunoglobulin conjugates and its substrates [15]. The conjugate consists of antibovine IgG conjugated to horseradish perioxidase while the substrate is hydrogen peroxide with donor chromogen of donor chromogen 2 (ABTS) that turns green in the presence of peroxidase [16].

\section{Materials and Methods}

This was a cross sectional study to be carried out in Mandera East Sub-county, Mandera County. According to [17], a cross sectional study is ideal in that it provides a point in time information that captures the opinions, attitudes, preferences, prevalence and factors of interest in research. The study population was made up of 10,458 households in Mandera East Sub-County where each household had on average 6 members. A formula by Fisher and Voorhees [18] was used to draw a sample population of 420 respondents from the population. The population is mainly rural and largely pastoralists keeping cattle, goats, donkeys, sheep, camels and often interact with the wildlife such as buffaloes and antelopes. Multistage sampling technique was used to determine the study participants in this study.

Mandera East Sub-county was purposively selected while Simple random sampling technique was used to select two divisions the Central and Khalalio divisions (Table 1). Simple random sampling was then used to determine two locations from each of the selected divisions. Four locations, the Central and Fiqo from Central Division and Khalalio and Bella from Khalalio Division were selected. All households were involved in the study until correct sample reached. Household heads were selected into the study and where not present, any other eldest member of the family who was mature was selected to participate in the study. Key informants included Mandera County Director of Public Health Services, Director of Veterinary services laboratory technologists pharmacists in Public and Private facilities. 
Table-1. The Sample Frame

\begin{tabular}{l|l|l|l|l|l}
\hline County & Sub county & Division & Location & $\begin{array}{l}\text { Households in } \\
\text { the population }\end{array}$ & $\begin{array}{l}\text { Households in } \\
\text { a Sample s }\end{array}$ \\
\hline Mandera & Mandera East & Central & Central & 740 & 118 \\
\hline & & & Fiqo & 580 & 95 \\
\hline & & Khalalio & Khalalio & 602 & 97 \\
\hline & & Bella & 695 & 110 \\
\hline Total & & 2617 & 420 \\
\hline
\end{tabular}

Source: Researcher (2016)

For Blood sample collection and handling, a respondent with recorded or reported history of fever during the current study was a handled as a suspected case. Fever was defined as any patient whose temperature was recorded by the clinician to be above $37^{\circ} \mathrm{C}$. Every respondent was asked to donate their brachial vein's blood which was taken with $5 \mathrm{ml}$ Vacutainer ${ }^{\circledR}$ tubes. The blood samples were centrifuged in 3000 rounds per minute for five minutes. Separated $1.5 \mathrm{ml}$ tubes of serum were kept in a cool box and transported to the Mandera Hospital laboratories for storage and testing.

Sera were tested with the RBPT for detection of antibodies to Brucellaabortus/melitensis. Positive sera were retested with using Serum Slow Agglutination Test (SSAT) according to manufacturer's instruction. To identify risk factors, socio-demographic variables like age, sex, education level and religion were assessed. In addition, occupational factors such as use of protective gear, animal species handled whether sick or healthy and if the respondents participated in animal handling were explored. Probable cases were respondents whose blood tested positive on the rapid testing by the Rose Bengal Plate Test while all respondents whose blood tested positive for brucellosis by Serum Slow Agglutination Test (SSAT) were confirmed cases.

The study included household heads or any eldest members of the household available at home during the study day. Only those who consented to the study were included. Household heads who were under treatment particularly on Antibiotic drugs or those who could not mentally stable were excluded. The study used questionnaire, key informant guides and Focus group discussion guides to collect the required data for this study. These study tools were both structured and unstructured in nature. Laboratory equipment and reagents were used for serological tests. The collected data was organized in descriptive statistics where measures of central tendency, dispersion, relative positions and measures of relations and associations were determined. In most circumstances, the data collected in descriptive survey research design are non-parametric [19] thus Chi-square test was used to test the research hypotheses. Analysis was done using SPSS Version 20.

\section{Results and Discussion}

\subsection{Demographic Characteristics}

The overall mean age was $44 \pm 13$ years (range 15-87) and median 44 years. About $29.3 \%$ of the respondents were aged between $35-45$ years where $86.2 \%$ were males (Table 2 ).

Table-2. Socio-demographic characteristics of the respondents

\begin{tabular}{|c|c|c|c|}
\hline Attribute & Category & Frequency $(\mathbf{N})$ & Percent (\%) \\
\hline \multirow[t]{6}{*}{ Age groups } & $15-25$ & 15 & 3.6 \\
\hline & $25-35$ & 91 & 21.7 \\
\hline & $35-45$ & 123 & 29.3 \\
\hline & $45-55$ & 112 & 26.7 \\
\hline & $55-65$ & 54 & 12.8 \\
\hline & $>65$ & 25 & 6.0 \\
\hline \multirow[t]{2}{*}{ Gender } & Male & 362 & 86.2 \\
\hline & Female & 58 & 13.8 \\
\hline \multirow[t]{4}{*}{ Marital status } & Single & 14 & 0.3 \\
\hline & Married & 371 & 88.3 \\
\hline & Separated/ Divorced & 24 & 0.6 \\
\hline & Widowed & 11 & 0.3 \\
\hline \multirow[t]{2}{*}{ Religion } & Muslim & 385 & 91.7 \\
\hline & Christian & 35 & 8.3 \\
\hline \multirow{6}{*}{$\begin{array}{l}\text { Level } \\
\text { education }\end{array}$} & Never been to school (Informal Education) & 22 & 5.2 \\
\hline & Never completed Primary school & 135 & 32.1 \\
\hline & Completed Primary School & 162 & 38.6 \\
\hline & Never completed Secondary school & 74 & 17.6 \\
\hline & Completed Secondary School & 21 & 5 \\
\hline & Post-Secondary School Education & 6 & 1.4 \\
\hline \multirow[t]{5}{*}{ Occupation } & Pastoralist & 210 & 50 \\
\hline & Agro-pastoralist & 27 & 6.4 \\
\hline & Farmer & 14 & 3.3 \\
\hline & Formal employment & 8 & 1.9 \\
\hline & Unemployed & 161 & 38.3 \\
\hline
\end{tabular}


The study showed that majority of the respondents (58.3\%) were married,91.7\%practiced Islam faith, and $38.6 \%$ had completed primary school while half of them were pastoralists $(50 \%)$ (Table 2).

\subsection{The Prevalence of Brucellosis}

The presence of Brucella antibodies was screened using Rose Bengal Plate Test (RBPT) and Serum Slow Agglutination Test (SSAT) and the results were presented in Table 3.

Table-3. Respondents RBPT and SSAT status

\begin{tabular}{l|l|l|l|l}
\hline \multirow{2}{*}{ Location } & RBPT & SSAT & Positive cases \\
\cline { 2 - 5 } & Negative cases & Positive cases & Negative cases & $27(66.0 \%)$ \\
\hline Central & $99(69.7 \%)$ & $43(30.3 \%)$ & $14(44 \%)$ & $13(46 \%)$ \\
\hline Khalalio & $105(66.1 \%)$ & $33(23.9 \%)$ & $15(54 \%)$ & $16(62.0 \%)$ \\
\hline Fiqo & $75(79.8 \%)$ & $19(20.2 \%)$ & $10(38.0 \%)$ & $4(44 \%)$ \\
\hline Bella & $37(80.4 \%)$ & $9(19.6 \%)$ & $5(56 \%)$ & $60(57.7 \%)$ \\
\hline Total & $316(75.2 \%)$ & $104(24.8 \%)$ & $44(42.3 \%)$ & $\chi 2=7.009 ; \mathrm{df}=3 ; \mathrm{p}=0.072$ \\
\hline Significance & $\chi 2=4.087 ; \mathrm{df}=3 ; \mathrm{p}=0.252$ & \multicolumn{2}{l}{} \\
\hline
\end{tabular}

Rose Bengal Plate Test (RBPT) indicated a prevalence of 24.8\% (95\% CI: 20.0-29.6) and Serum Slow Agglutination Test (SSAT) indicated that the prevalence was at 14.3\% (95\% CI: 8.7-19.9) among the respondents. Respondents from Central location had the highest seroprevalence of $30.3 \%$ as detected through RBPT while SSAT detected $66.0 \%$. However respondents from Bella location had the least seroprevalence of $19.6 \%$ and $44 \%$ as detected through RBPT and SSAT tests respectively. However there was no significant statistical difference between the location of the respondent and his/her seroprevalence as detected through $\operatorname{RBPT}(\chi 2=4.087 ; \mathrm{df}=3 ; \mathrm{p}=0.252)$ and as detected through $\operatorname{SSAT}(\chi 2=7.009 ; \mathrm{df}=3 ; \mathrm{p}=0.072)$

\subsection{The Prevalence of Brucellosis Relation to Marital Status}

The study examined the relationship between the respondents' seroprevalence to brucellosis and their marital status and the results were presented in table 4.

Table-4. Relationship of marital status of the respondents and sero-prevalence of brucellosis

\begin{tabular}{|c|c|c|c|c|c|c|}
\hline \multirow[t]{2}{*}{ Variable } & \multicolumn{3}{|l|}{ RBPT } & \multicolumn{3}{|l|}{ SSAT } \\
\hline & Negative & Positive & Significance & Negative & Positive & Significance \\
\hline \multicolumn{7}{|c|}{ Marital status } \\
\hline Single & $10(71 \%)$ & $4(29 \%)$ & \multirow{4}{*}{$\begin{array}{l}\chi 2=4.203 \\
p=0.235^{*}\end{array}$} & $1(25 \%)$ & $3(75 \%)$ & \multirow{4}{*}{$\begin{array}{l}\chi 2=6.080 \\
p=0.092 *\end{array}$} \\
\hline Married & $282(76 \%)$ & $89(24 \%)$ & & $39(43 \%)$ & $51(57 \%)$ & \\
\hline Separated & $16(67 \%)$ & $8(33 \%)$ & & $3(43 \%)$ & $4(57 \%)$ & \\
\hline Widowed & $8(73 \%)$ & $3(27 \%)$ & & $1(33 \%)$ & $2(67 \%)$ & \\
\hline Total & $316(75 \%)$ & $104(25 \%)$ & & $44(42 \%)$ & $60(58 \%)$ & \\
\hline
\end{tabular}

Soure: Study Data (2016)

The study showed that highest brucellosis seroprevalence was among separated respondents (33\%) as detected through RBPT and among widowed (67\%) as confirmed through SSAT. However there was no significant statistical relationship between the marital status of the respondent and his/her seroprevalence as detected through RBPT $\left(\chi^{2}=4.203 ; \mathrm{df}=3 ; \mathrm{p}=0.235\right)$ and as detected through SSAT $(\chi 2=6.08 ; \mathrm{df}=3 ; \mathrm{p}=0.092)$.

\subsection{The Prevalence of Brucellosis in Relation to Gender and Age of the Respondents}

The study examined the relationship between the respondents' seroprevalence to brucellosis with their gender and with age and the results were presented in table 4.4 below.

Table-5. Relationship of gender and age of the respondent with sero-prevalence of Brucellosis

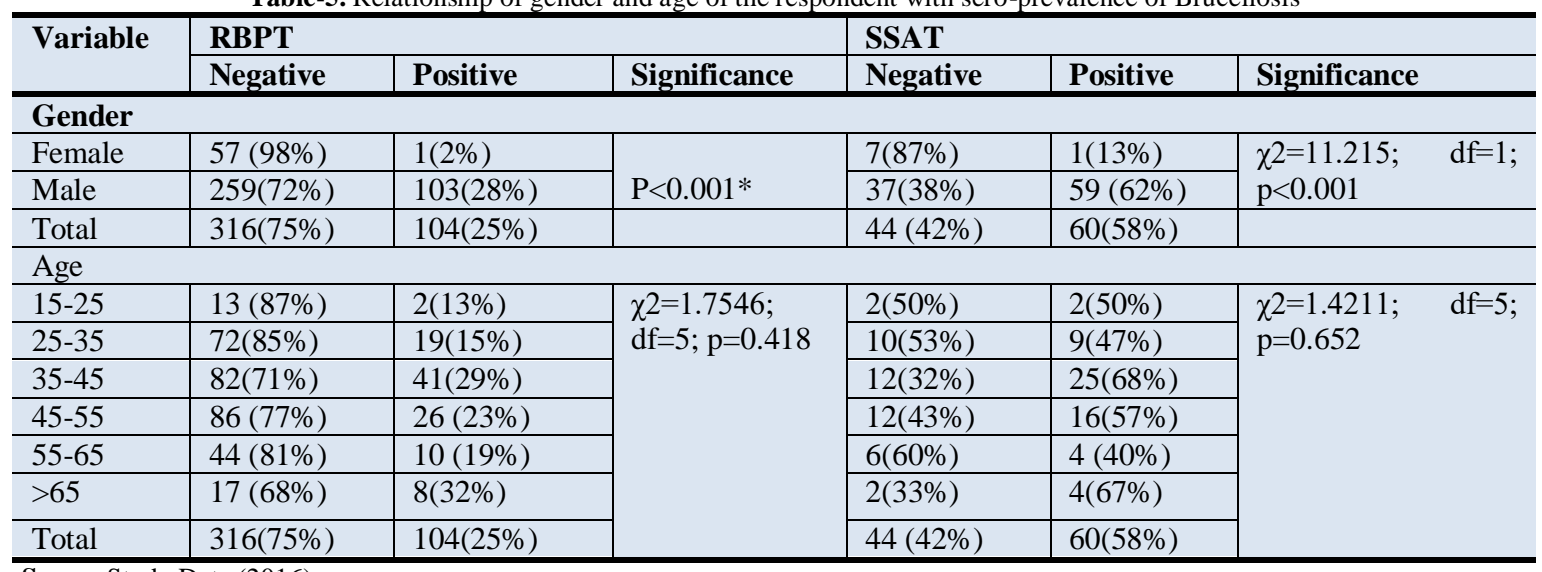

Soure: Study Data (2016) 
The study showed that the seroprevalence was higher among the male respondents $(28 \% ; n=103)$ as detected through RBPT and $(62 \% ; n=59)$ confirmed through SSAT. There was high significant association between respondents' gender and his $\backslash$ her seroprevalence as tested through RBPT $(\mathrm{P}<0.001)$ and through SSAT $(\mathrm{P}<0.001)$. The respondents whose age was between $35-45$ years $(29 \%, n=41)$ and $(68 \%, n=25)$ as tested through RBPT and SSAT respectively. However the study did not show any significant statistical association between respondents' age and seroprevalence as tested through $\operatorname{RBPT}(\chi 2=1.7546 ; \mathrm{df}=5 ; \mathrm{p}=0.418)$ and through $\operatorname{SSAT}(\chi 2=1.4211 ; \mathrm{df}=5$; $\mathrm{p}=0.652)$

\subsection{The Prevalence of Brucellosis in Relation Education Level and Occupation of the Respondents}

The study compared the number of respondents' seroprevalence to brucellosis with their education level and occupation and the results are presented in table 2.

Table-6. Relationship of education level and occupation of the respondent with sero-prevalence of brucellosis

\begin{tabular}{|c|c|c|c|c|c|c|}
\hline \multirow[t]{2}{*}{ Variable } & \multicolumn{3}{|l|}{ RBPT } & \multicolumn{3}{|l|}{ SSAT } \\
\hline & Negative & Positive & Significance & Negative & Positive & Significance \\
\hline \multicolumn{7}{|c|}{ Level of Education } \\
\hline No school & $19(86 \%)$ & $3(14 \%)$ & \multirow{6}{*}{$\begin{array}{l}\chi 2=4.160 \\
d f=5 \\
p=0.519\end{array}$} & $2(40 \%)$ & $3(60 \%)$ & \multirow{6}{*}{$\begin{array}{l}\chi 2=2.427 \\
\mathrm{p}=0.781 \%\end{array}$} \\
\hline $\begin{array}{l}\text { Incomplete } \\
\text { Primary }\end{array}$ & $98(73 \%)$ & $37(27 \%)$ & & $14(37 \%)$ & $24(63 \%)$ & \\
\hline $\begin{array}{l}\text { Completed } \\
\text { primary }\end{array}$ & $123(76 \%)$ & $39(24 \%)$ & & $17(46 \%)$ & $20(54 \%)$ & \\
\hline $\begin{array}{l}\text { Incomplete } \\
\text { secondary }\end{array}$ & $53(72 \%)$ & $21(28 \%)$ & & $8(42 \%)$ & $11(58 \%)$ & \\
\hline $\begin{array}{l}\text { Complete } \\
\text { secondary }\end{array}$ & $17(81 \%)$ & $4(19 \%)$ & & $2(50 \%)$ & $2(50 \%)$ & \\
\hline $\begin{array}{l}\text { College/ } \\
\text { University }\end{array}$ & $6(100 \%)$ & $0(0 \%)$ & & $1(100 \%)$ & $0(0 \%)$ & \\
\hline Total & $316(75 \%)$ & $104(25 \%)$ & & $44(42 \%)$ & $60(58 \%)$ & \\
\hline \multicolumn{7}{|l|}{ Occupation } \\
\hline Pastoralist & $153(73 \%)$ & $57(27 \%)$ & \multirow{5}{*}{$\begin{array}{l}\chi 2=5.202 ; \quad d f=4 ; \\
p=0.268\end{array}$} & $21(35 \%)$ & $39(65 \%)$ & \multirow{5}{*}{$\begin{array}{l}\chi 2=6.463 \\
p=0.138 *\end{array}$} \\
\hline $\begin{array}{l}\text { Agro- } \\
\text { pastoralist }\end{array}$ & $19(70 \%)$ & $8(30 \%)$ & & $3(60 \%)$ & $2(40 \%)$ & \\
\hline Farmer & $9(64 \%)$ & $5(36 \%)$ & & $1(33 \%)$ & $2(67 \%)$ & \\
\hline $\begin{array}{l}\text { Formal } \\
\text { employment }\end{array}$ & $5(62 \%)$ & $3(38 \%)$ & & $1(50 \%)$ & $1(50 \%)$ & \\
\hline Unemployed & $130(81 \%)$ & $31(19 \%)$ & & $18(53 \%)$ & $16(47 \%)$ & \\
\hline Total & $316(75 \%)$ & $104(25 \%)$ & & $44(42 \%)$ & $60(58 \%)$ & \\
\hline
\end{tabular}

Source: Study Data (2016)

The study showed that the highest brucellosis seroprevalence was least among those respondents with complete secondary and college education level. This observation was made among the unemployed too who had the least seroprevalence to the disease $(19 \%, \mathrm{n}=31)$ in tests carried out through RBPT and $(47 \%, \mathrm{n}=16)$ as confirmed through SSAT. However the study did not show any significant statistical association between respondents' level of education and seroprevalence as tested through RBPT $(\chi 2=4.160 ; \mathrm{df}=5, \mathrm{p}=0.519)$ and through $\operatorname{SSAT}\left(\chi^{2}=5.202\right.$; $\mathrm{df}=4 ; \mathrm{p}=0.268$ )

The study established a high prevalence of brucellosis (24.8\%) for Rose Bengal Plate Test (RBPT) and 14.3\% for Serum Slow Agglutination Test (SSAT) among community members in Mandera East Sub-County. This was probably because the communities here are pastoralists who are in constant contact with animals. The findings of this study are consistent with Racloz, et al. [20] who studied the persistency of brucellosis in pastoral systems. Very high prevalence $(24.5 \%$ ) has been reported in the Northern Sudan and 6.9\% in Tanzania [21]. Studies done by Muriuki, et al. [22] and Richards, et al. [23] in Kenya showed that human brucellosis is more common where extensive cattle production systems predominate with almost a prevalence of $14 \%$ to $21 \%$. However the result from the study was higher than the $0.1 \%$ to $10.1 \%$ reported among high-risk people in other countries Zinsstag, et al. [24].

The study showed that people of age between 15-45 years of age were affected more, this was consistent with report from northern Saudi Arabia which found that cases of brucellosis occurred mainly in individuals aged 13-40 years with younger than 13 years and less in those aged 40-60 years [9]. This age group plays an important role in livestock herding and birthing and have direct contact with animals and aborted materials. However that seropositives were found in all age groups, this may indicate ongoing exposure and transmission of brucellosis.

The study showed a significant difference between gender and RBPT status of the respondents. Men were more infected than their women counterparts. This would be because men were much more in contact with livestock. This is consistent with study done by Mantur and Amarnath [25]; Young, et al. [26] who showed that brucellosis may be more common in males in areas where it is an occupational hazard of farmers and shepherds, butchers or veterinarians. 
Marital status, age, level of education, and occupational of the respondents didn't influence their RBPT or SSAT status. Whether married or not married, at any age, any level of education and in whichever occupation Brucellosis infection can occur providd one is in contact with infected animals or their products. The results of this study concurs with results of work done by Mantur, et al. [27] who observed that both males and females in all age groups are affected equally in particular when dairy is the most common source of infection. Likewise [28] observed that level of education did not always translate to good hygienic standards. Similar results were found in Uganda by Nakavuma, et al. [29] who observed that Socio-demographic factors (age, sex, education level, religion) were all not significantly associated with Brucella infection unlike in other studies.

\section{Conclusions, Recommendation and Suggestions for Further Research}

The prevalence of brucellosis was $24.8 \%$ (95\% CI: 20.0-29.6) using Rose Bengal Plate Test (RBPT) and 14.3\% (95\% CI: 8.7-19.9) using Serum Slow Agglutination Test (SSAT) among community members in Mandera East Sub-County. This study recoomends that Sub-county of Mandera East should find out an appropriate way of dealing with the high prevalence rate of brucellosis in the area. There is a need for further study on the effects of Brucellosis infection among community members in Mandera East Sub-County

\section{References}

[1] Kaufmann, A. F., 2006. "Airborne spread of brucellosis." Ann N Y AcadSci, vol. 353, pp. 105-114

[2] Pappas, G., Papadimitriou, P., Akritidis, N., Christou, L., and Tsianos, E. V., 2006. "The new global map of human brucellosis." Lancet Infect Dis. Feb., vol. 6, pp. 91-9.

[3] Gul, A., 2007. "Standard and novel therapeutic approaches to Behçet's disease." Drugs, vol. 67, pp. 20132022.

[4] Young, E. J., 1995. "An overview of human brucellosis." Clinical Infectious Diseases, vol. 21, pp. $283-289$.

[5] Glynn, M. K. and Lynn, T. V., 2008. "Zoonosis update." AVMA, vol. 233, pp. 900-908.

[6] Matika, K., Fèvre, E. M., Waiswa, C., Kaboyo, W., De Clare Bronsvoort, M. B., Eisler, C. M., and Welburn, S. C., 2010. Human brucellosis in urban and peri-urban areas of kampala, uganda, annals of animal biodiversity and emerging diseases prediction and prevention. New York Academy of Science.

[7] Kenya Department of Veterinary Serivices, 1999-2010. Annual reports. Ministry of Livestock Development Kenya.

[8] Olsen, S. C., 2013. "Recent developments in livestock and wildlife brucellosis vaccination." Rev. Sci. Tech., vol. 32, pp. 207-17.

[9] Fallatah, S. M., Oduloju, A. J., Al-Dusari, S. N., and Fakunle, Y. M., 2005. "Human brucellosis in Northern Saudi Arabia." Saudi Med J., vol. 26, pp. 1562-6.

[10] Alp, E. and Doganay, M., 2008. "Current therapeutic strategy in spinal brucellosis." International Journal of Infectious Diseases, vol. 12, pp. 573-577.

[11] Celebi, G., Külah, C., Kiliç, S., and Ustündag, G., 2007. "Asymptomatic Brucellabacteraemia and isolation of Brucellamelitensisbiovar 3 from human breast milk." Scand J. Infect Dis., vol. 39, pp. 205-8.

[12] Blake, G. E., Manthei, C. A., and Goode Jr, E. R., 1952. "A milk plate test for the detection of brucellosis." Journal of American Veterinary Medical Association, vol. 120, pp. 1-6.

[13] MacMillan, A. P. and Cockrem, D. S., 1985. "Reduction of non-specific reactions to the brucella abortus serum agglutination test by the addition of edta." Research in Veterinary Science, vol. 28, pp. 288-291.

[14] Laing, J. A., Brinley, M., and Wagner, W. C., 1988. Fertility and infertility in veterinary practise. Ballière Tindall.

[15] Sutherland, S. S. and Searson, J., 1990. The immune response to brucella abortus: The humoral response. Animal brucellosis. Nielsen, $k$. And duncan, jr ed. Florida, USA: CRC Press, Inc., pp. 65-81.

[16] Flores, E., Heck, F., Nielsen, K., Pugh, R., Rosenbaum, T., and Band, W. G., 1984. Comparative assessment of antibody isotypes to $b$. Abortus by Primary of Secondary Binding Assay.

[17] Saunders, M., Lewis, P., and Thornhill, A., 2007. Research methods for business students. 4th ed. London: Prentice Hall.

[18] Fisher, G. J. and Voorhees, J. J., 1998. "Molecular mechanisms of photoaging and its prevention by retinoic acid: Ultraviolet irradiation induces map kinase signal transduction cascades that induce ap-1-regulated matrix metalloproteinases that degrade human skin in vivo." Journal of Investigative Dermatology Symposium Proceedings, vol. 3, pp. 61-68.

[19] Brunt, P., 1997. Market research in travel and tourism. Butterworth-Heinemann Ltd.

[20] Racloz, V., Schelling, E., Chitnis, N., Roth, F., and Zinsstag, J., 2013. "Persistence of brucellosis in pastoral systems." OIE Revue Scientifique et Technique, vol. 32, pp. 61-70.

[21] Angara, T. E. E., Ismail, A. A., Agab, H., and Saeed, N. S., 2004. Sero-prevalence of bovine brucellosis in Kuku Dairy Scheme. Khartoum North, Sudan.

[22] Muriuki, S. M. K., Murugu, R. K., Munene, E., Karere, G. M., and Chai, D. C., 1998. "Some gastrointestinal parasites of zoonotic (public health) importance commonly observed in old world non-human primates in Kenya." Acta Tropica, vol. 71, pp. 73-82.

[23] Richards, A. L., Jiang, J., Omulo, S., Dare, R., Abdirahman, K., Ali, A., and Njenga, M. K., 2010. "Human infection with rickettsia felis, Kenya." Emerging Infectious Diseases, vol. 16, p. 1081. 
[24] Zinsstag, J., Schelling, E., Roth, F., Bonfoh, B., De Savigny, D., and Tanner, M., 2007. "Human benefits of animal interventions for zoonosis control." Emerging Infectious Diseases, vol. 13, p. 527.

[25] Mantur, B. G. and Amarnath, S. K., 2008. "Brucellosis in India—a review." Journal of Biosciences, vol. 33, pp. 539-547.

[26] Young, E. J., Tarry, A., Genta, R. M., Ayden, N., and Gotuzzo, E., 2000. "Thrombocytopenic purpura associated with brucellosis: report of 2 cases and literature review." Clinical Infectious Diseases, vol. 31, pp. 904-909.

[27] Mantur, B. G., Amarnath, S. K., and Shinde, R. S., 2007. "Review of clinical and laboratory features of human brucellosis." Indian Journal of Medical Microbiology, vol. 25, p. 188.

[28] Waller, D. S., Fam, K. S., and Zafer Erdogan, B., 2005. "Advertising of controversial products: a crosscultural study." Journal of Consumer Marketing, vol. 22, pp. 6-13.

[29] Nakavuma, J., Ssebunya, T. K., and Asibo, J. O., 1999. "Serosurvey of Brucella abortus in cattle and goats in Central and Southern Uganda." Uganda Journal of Agricultural Sciences, vol. 4, pp. 13-18. 